\title{
ANALISIS DAN PERANCANGAN SISTEM PENDUKUNG PENGAMBILAN KEPUTUSAN SELEKSI PENERIMA BERAS UNTUK KELUARGA MISKIN (RASKIN)
}

\author{
Khairil Hamdi ${ }^{1}$, Silvialista Putri² ${ }^{2}$ dan Budi Sunaryo ${ }^{3}$ \\ ${ }^{1,2}$ Jurusan Sistem Informasi, STMIK Jayanusa, Padang, Jl. Olo Ladang No. 1, Kec. Padang Bar, Kota Padang, \\ Sumatera Barat 25000 \\ ${ }^{3}$ Jurusan Teknologi Rekayasa komputer jaringan, Fakultas Teknologi Industri, Universitas Bung Hatta, Jalan \\ Gajah Mada No.19 Nanggalo Padang 25173.
}

e-mail: ${ }^{1}$ khairilhamdi@jayanusa.ac.id, ${ }^{2}$ silvialista.p@gmail.com, ${ }^{3}$ budi.sunaryo@bunghatta.ac.id

\begin{abstract}
Article history Received Sep 3, 2020

Revised Okt 1, 2020

Accepted Nov 12

2020

Available online Nov 30, 2020

Keywords

Analysis, Design,

Decision Support

System, RASKIN

The Decision Support System (SPK) for rice recipient selection for poor families is a system used to assist in the decision-making process in determining who is eligible to receive rice for poor families (RASKIN). This system is designed to avoid mistakes and cheating that may occur. There are two methods in this research: data search method (literature study, observation, interview) while for system development using waterfall (communication, plan, modeling, construction and deployment). The conclusion of this study accelerates the decision-making process of rice recipient selection for poor families so that it can be easy and practical to use and able to display reports quickly and accurately.

Keywords: Analysis, Design, Decision Support System, RASKIN
\end{abstract}

\section{Abstrak}

Sistem Pendukung Keputusan (SPK) seleksi penerima beras untuk keluarga miskin merupakan sebuah sistem yang digunakan untuk membantu dalam proses pengambilan keputusan dalam menentukan siapa saja yang layak menerima beras untuk keluarga miskin (RASKIN). Sistem ini dirancang untuk menghindari kesalahan-kesalahan dan kecurangan-kecurangan yang mungkin terjadi. Terdapat dua metode dalam penelitian ini: metode pencarian data (studi literatur, observasi, wawancara) sedangkan untuk pengembangan sistem menggunakan waterfall (komunikasi, rencana, pemodelan, konstruksi dan deployment). Kesimpulan dari penelitian ini mempercepat proses pengambilan keputusan seleksi penerimaaan beras untuk keluarga miskin sehingga bisa mudah dan praktis untuk digunakan serta mampu menampilkan laporan secara cepat dan akurat.

Keywords: Analisis, Perancangan, Sistem Pendukung Keputusan, RASKIN

\section{PENDAHULUAN}

Krisis global yang terjadi pada saat sekarang ini berdampak besar pada negara negara maju ataupun negara negara yang sedang berkembang. Perekonomian dunia yang tidak stabil menyebabkan krisis keuangan pada perusahaan perusahaan dan banyak orang yang kehilangan pekerjaan. Dampak krisis ekonomi yang terjadi di Indonesia sudah cukup lama, sebagai negara yang sedang berkembang. Akibat dari krisis ekonomi yang berkepanjangan menjadikan kemampuan penduduk Indonesia semakin sulit dalam memenuhi berbagai kebutuhan mendasar seperti halnya makanan pakaian, dan perumahan. Perjuangan hidup sehari hari yang demikian berat masih harus dihadapi setiap orang untuk mendapatkan makanan yang cukup guna memenuhi kebutuhan sendiri dan keluarganya. Dampak keseluruhan dari kondisi ini adalah menurunnya tingkat kesejahteraan di sektor 
kehidupan tertentu masyarakat Indonesia. Salah satunya program pemerintah dalam menanggulangi krisis ini adalah dengan menyediakan menyediakan subsidi beras, caranya adalah dengan memberi bantuan beras bulanan kepada rakyat yang kekurangan di seluruh Indonesia. Dalam menyalurkan beras kualitas medium terhadap keluarga prasejahtera (KPS) atau keluarga miskin disetiap daerah diseluruh Indonesia. Metode yang digunakan dalam pengambilan keputusan penerima beras untuk keluarga miskin (Raskin) masih menggunakan cara manual yang digunakan dalam bentuk kertas, sehingga memerlukan waktu lama untuk pengolahan dan terkendala besar pada penyimpanan dan pencarian arsip yang telah tersimpan jika akan dicocokkan sebagai pedoman yang baru diperoleh. Proses seleksi penerima raskin yang masih manual menyebabkan penilaiannya lebih bersifat subyektif, banyak kelurga yang seharusnya tidak dapat tapi dapat dan sebaliknya.

Untuk itu perlu dibangun sistem untuk menghindari kesalahan-kesalahan dan kecurangankecurangan yang diperbuat oleh pihak tertentu. Dalam hal ini digunakan sistem pendukung keputusan (SPK). Sistem pendukung keputusan (SPK) adalah bagian dari Sistem Informasi berbasis komputer yang termasuk sistem berbasis pengetahuan (management pengetahuan) yang dipakai untuk pengambilan keputusan dalam suatu organisasi atau sebuah perusahaan. Sistem pendukung keputusan ini membantu melakukan penilaian setiap keluarga miskin melakukan perubahan kriteria, dan perubahan nilai bobot. Hal ini berguna untuk mengambil keputusan yang terkait masalah seleksi penerima beras untuk keluarga miskin (Raskin). Sistem ini menggunakan beberapa kriteria untuk keluarga miskin diantaranya pekerjaan tidak tetap, penghasilan maksimal Rp. 15.000, -perhari, orangtua tidak ada yang menanggung, jumlah keluarga minimal 3 orang dari masing - masing keluarga, kemudian kriteria yang telah ditentukan diberikan masingmasing bobot penilaian. Semakin tinggi bobot penilaian maka semakin tinggi total penilaian terhadap keluarga yang berhak menerima raskin.

\section{Tinjauan Pustaka}

\subsection{Perancangan}

Perancangan sistem adalah sekumpulan aktivitas yang menggambarkan secara rinci bagaimana sistem akan berjalan. Hal itu bertujuan untuk menghasilkan produk perangkat lunak yang sesuai dengan kebutuhan user [1]. Sedangkan definisiyang lain perancangan sistem adalah sebuah kegiatan merancang dan menentukan cara mengolah sistem informasi dari hasil analisa sistem sehingga dapat memenuhi kebutuhan dari pengguna termasuk diantaranya perancangan user interface, data dan aktivitas proses [2]. Salah satu metode yang digunakan untuk pengembangan sistem yaitu Waterfall yang memiliki 5 langkah: komunikasi, rencana, pemodelan, kontstruksi dan deployemen [3].

\subsection{Sistem Pendukung Keputusan}

Menurut O'Brien dalam Taufiq (2018) Sistem pendukung keputusan adalah sistem informasi berbasis computer yang memberikan dukungan informasi interaktif untuk manajer dan pebisnis professional selam proses pengambilan keputusan [4].

SPK penentuan penerimaan RASKIN bermanfaat untuk membantu pihak kelurahan kota Uneng dalam menentukan penduduk yang berhak menerima beras miskin agar penerima sesuai dengan kriteria [5]. Selain sistem pendukung keputusan untuk penentuan warga penerima RASKIN, Sistem pendukung keputusan juga dilakukan untuk proses kenaikan pangkat pegawai di BKPSDM Kota Tangerang dengan menggunakan metode AHP [6]. Selain itu peran sistem pendukung keputusan berbasis komputer juga dilakukan dalam proses peniliana kinerja pegawai, dimana sistem pendukung keputusan memiliki dampak yang luar biasa khsusnya dalam bidang kecepatan proses, kecepatan untuk menampilkan laporan secara otomatis dan memiliki akurasi yang tinggi dalam bidang penilaian kienerja pegawai [7].

\subsection{Pengertian Raskin}

Penyaluran RASKIN (Beras untuk Rumah Tangga Miskin) sudah dimulai sejak 1998. Krisis moneter tahun 1998 merupakan awal pelaksanaan RASKIN yang bertujuan untuk memperkuat ketahanan pangan rumah tangga terutama rumah tangga miskin. Pada awalnya disebut program Operasi Pasar Khusus (OPK), kemudian diubah menjadi RASKIN mulai tahun 2002, RASKIN diperluas fungsinya tidak lagi menjadi program darurat (social safety net) melainkan sebagai bagian dari program perlindungan sosial masyarakat. Penentuan kriteria penerima manfaat RASKIN seringkali menjadi persoalan yang rumit. Dinamika data kemiskinan memerlukan adanya kebijakan lokal melalui musyawarah Desa/Kelurahan. Musyawarah ini menjadi kekuatan utama program 
untuk memberikan keadilan bagi sesama rumah tangga miskin [8].

Program Raskin adalah salah satu program penanggulangan kemiskinan dan perlindungan sosial di bidang pangan yang diselenggarakan oleh Pemerintah Pusat berupa bantuan beras bersubsidi kepada rumah tangga berpendapatan rendah (rumah tangga miskin dan rentan). Program Raskin bertujuan untuk mengurangi sebagian beban pengeluaran rumah tangga sasaran dalam memenuhi kebutuhan pangan pokok dalam bentuk beras. Efektivitas Raskin sebagai perlindungan sosial dan penanggulangan kemiskinan sangat bergantung pada kecukupan nilai transfer pendapatan dan ketepatan sasaran kepada kelompok miskin dan rentan [9].

\section{Metode Penelitian}

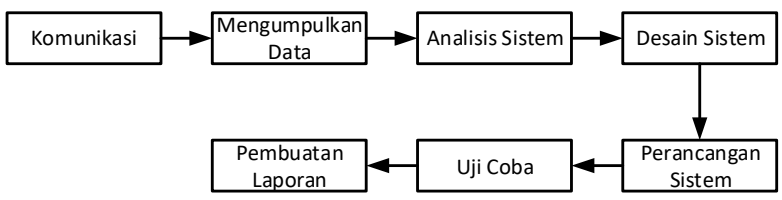

Gambar 1 Metode penelitian

Gambar 1 tentang metode penelitian yang dilakukan diatas menjelaskan 7 langkah, yang dimulai dari Komunikasi yang dilanjutkan Mengumpulkan Data sampai dengan Pembuatan laporan akhir dari sistem yang sudah dikembangkan.

\section{Analisa Dan Pembahasan}

\subsection{Analisa Sistem Berjalan}

Berikut ini gambaran umum sistem yang sedang berjalan pada sistem informasi dalam seleksi penerima beras untuk keluarga miskin (RASKIN):

1. Perangkat RT dan RW melakukan pendataan kepada Rumah Tangga Miskin (RTM) dengan menggunakana form pendataan RTM.

2. Perangkat RT dan RW Membuat daftar RTM berdasarkan rekap pendataan.

3. Kelurahan menerima daftar RTM dari Perangkat RT dan RW, selanjutnya mengisikannya kedalam rekap indicator kemiskinan.

4. Kelurahan akan mencek, mensurvai dan memberikan penilaian kepada RTM, dan mengisikan hasilnya kedalam formulir indicator kemiskinan.

5. Kelurahan akan menganalisa berdasarkan formulir indicator kemiskinan dan menentukan
RTM yang berhak menerima RASKIN, serta memberikannya kepada Kecamatan.

6. Kelurahan akan membuat kartu RASKIN, dan membagikannya langsung kepada RTM.

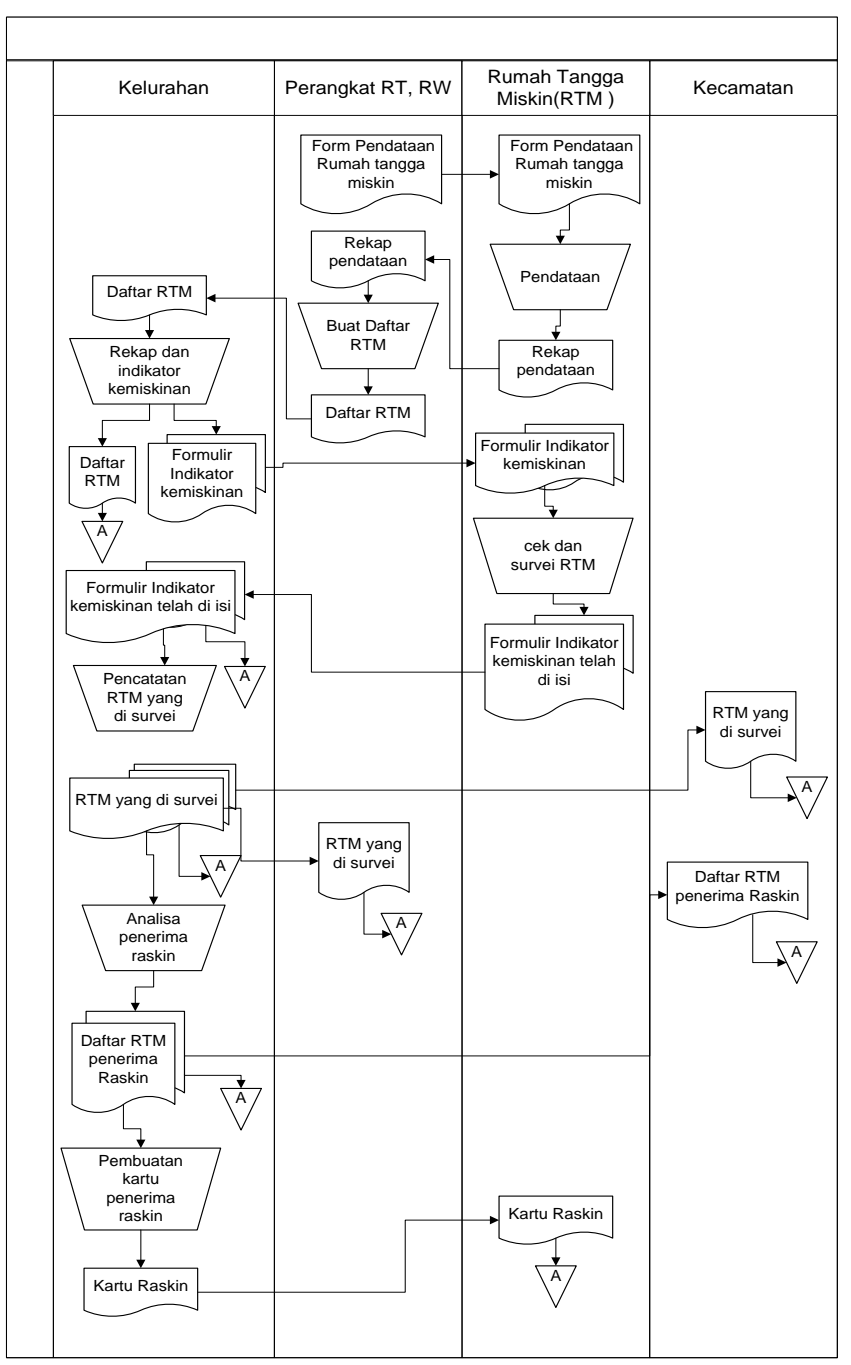

Gambar 2 Aliran sistem yang berjalan 


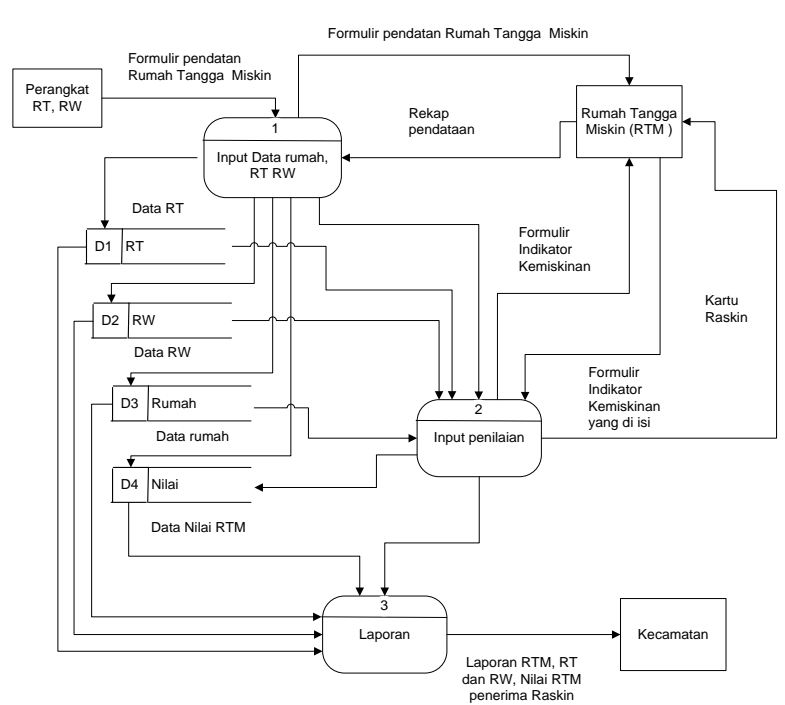

Gambar 3 Data Flow Diagram

Data Flow diatas menjelaskan 3 proses dimana proses pertama dimulai dengan Input data rumah, dilanjutkan proses yang kedua yaitu input penilaian atau proses penilaian yang dilakukan dan langkah yang ketiga pembuatan laporan. Laporan itu berisi tentang laporan RTM, RT dan RW hasil proses penilaian penerima Raskin. Selanjutnya laporan tersebut di berikan kepada Kecamatan.

\section{Entity Relationship Diagram}

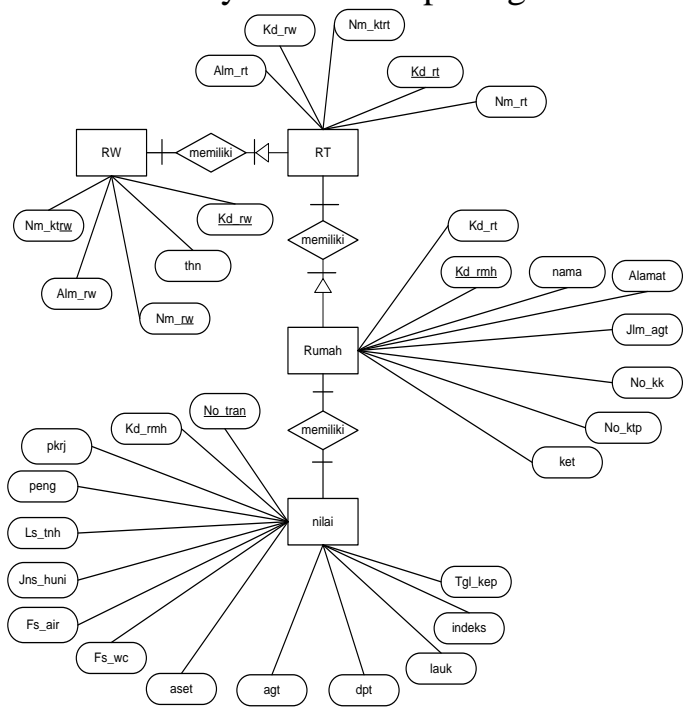

Gambar 4 Entity Relationship Diagram

Entity Relationship Diagram (ERD) pada gambar 4 diatas terdapat 4 entitas terdiri dari RW dimana masing-masing RW memiliki RW dan masing-masig RT memiliki Rumah dimana Rumah itulah yang akan dinilai dengan kriteria: pkj: pekerjaan, peng: penghasilan, ls_tnh: luas tanah, jns_huni: jenis lantai hunian, fs_air: fasilitas air bersih, fs_ws: fasilitas wc yang dimiliki, asset: kepemilikan aset, agt: jumlah anggota keluarga yang ada dalam rumah tersebut, dpt: pendapatan total perhari, lauk: konsumsi lauk pauk perbulan.

\section{Form Menu}

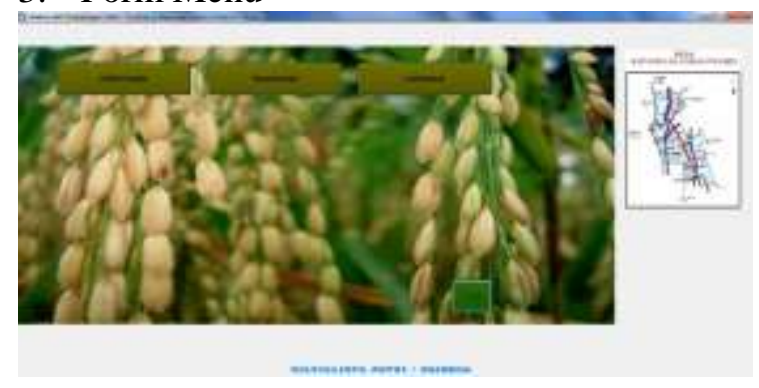

\section{Gambar 5 Form Menu}

Dalam gambar 5 diatas menunjukkan form utama tampilan dari sistem pendukung pengambilan keputusan seleksi penerima beras untuk keluarga miskin (RASKIN) dimana kemampuan tampilan utama mampu digunakan untuk melakukan input data, transaksi dan laporan secara otomatis akan ditampilkan.

\section{Form RW}

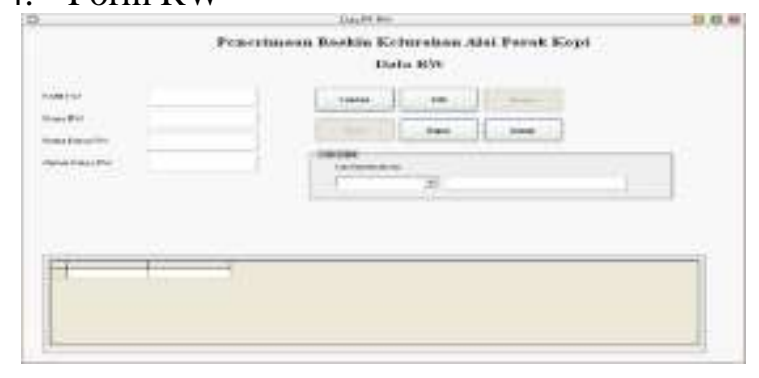

\section{Gambar 6 Form RW}

Gambar 6 diatas menjelaskan form isian dari sisi pengguna Rukun Warga (RW). Inputan yang bisa dilakukan: Ketua RW, Nama RW, Nama ketua RW dan alamat ketua RW.

\section{Form RT}




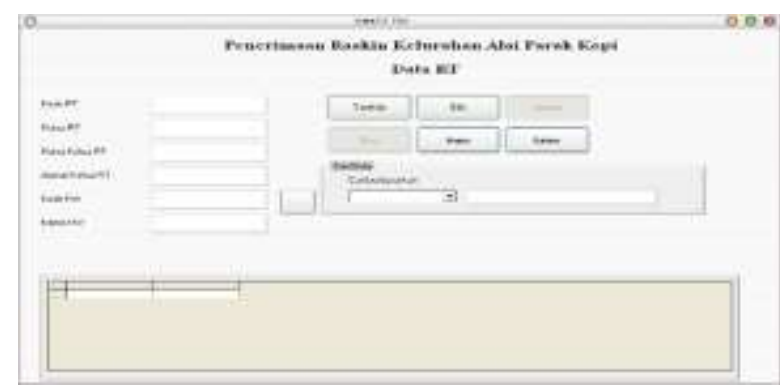

Gambar 7 Form RT

Pada gambar 7 diatas menjelaskan aplikasi inputan dari pengguna RT. Yang diinput yaitu kode RT, Nama RT, Nama ketua RT, Alamat ketua RT, Kode RW dan yang terakhir adalah nama RW. Dalam tampilan diatas bisa digunakan untuk melakukan tambah data, edit data, hapus data dan keluar. Selain itu juga bisa digunakan untuk proses pencarian data.

\section{Form Rumah Tangga Miskin}

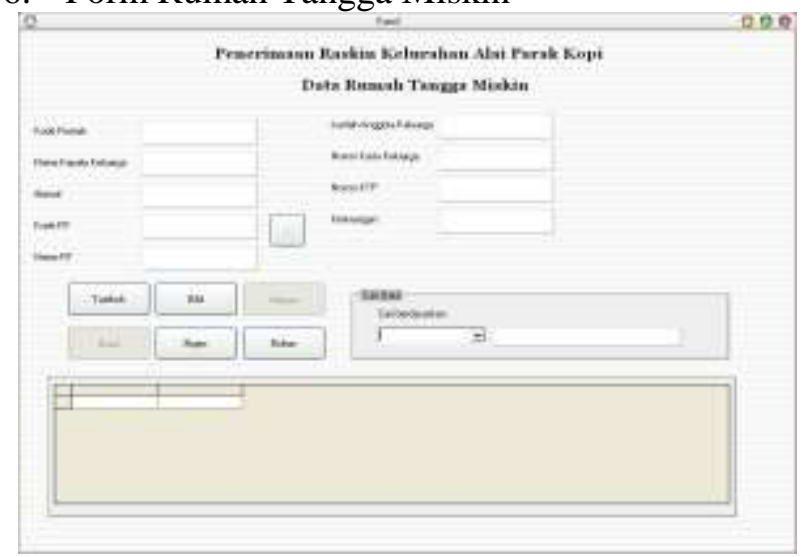

Gambar 8 Form Rumah Tangga Miskin

Pada gambar 8 diatas menjelaskan inputan status warga miskin yang akan dinilai, data warga yang dibutuhkan terdiri dari: kode rumah, nama kepala keluarga, alamat, kode RT, Nama RT, Jumlah anggota keluarga, nomor kartu keluarga, nomor ktp dan keterangan. Sama seperti gambar 7 proses yang dilakukan untuk input data, simpan data, hapus data serta bisa digunakan untuk proses pencarian melalui cari data.

7. Form Penilaian Rumah Tangga Miskin

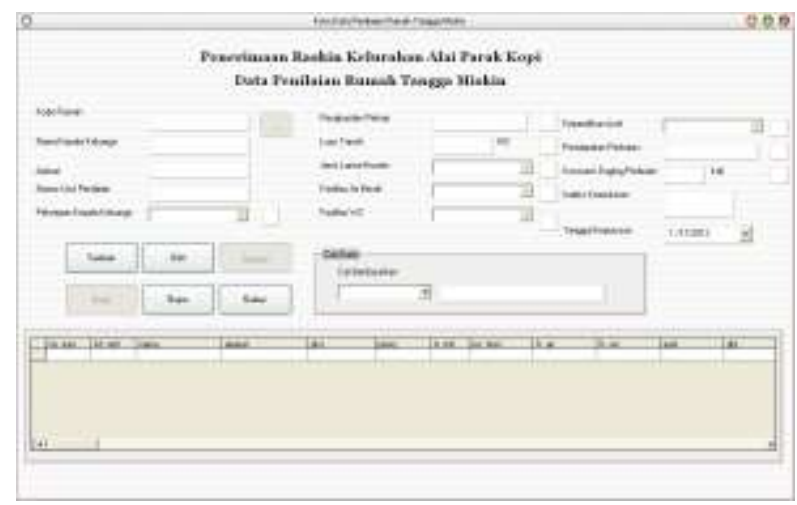

Gambar 9 Form Penilaian Rumah Tangga Miskin

\section{Kesimpulan}

Berdasarkan pengamatan dan analisa selama melakukan pengumpulan data pada Kantor Lurah Alai Parak Kopi Padang, maka dapat diambil beberapa kesimpulan: Dengan sistem baru yang dilengkapi aplikasi program yang dibuat dengan pemrograman MySQL dan Visual Basic 6.0 akan mempermudah dan mempercepat proses pengambilan keputusan seleksi penerimaaan beras untuk keluarga miskin. Dengan merancang sistem yang baru ini, aplikasi program yang dirancang sedemikian rupa dapat digunakan dengan mudah dan praktis oleh user. Sistem pendukung keputusan ini akan memberikan proses pembuatan laporan secara cepat dan akurat yang dibutuhkan oleh lembaga.

\section{Daftar Pustaka}

[1] J. W. Satzinger, R. B. Jackson and S. D. Burd, 2011. Systems Analysis and Design in a Changing World, Sixth edition

[2] O'Brien \& Marakas.2010. Management Information Systems. Eighth Edition. New York: McGraw-Hill/Irwin

[3] Pressman, R.S. (2010), Software Engineering: a practitioner's approach, McGraw-Hill, New York.

[4] Taufiq, R, 2018. Pengantar Sistem Informasi. Jakarta. Mitra Wacana Media.

[5] Wolo, P. Paseng, ASM dan Roberth, YW. 2019. Sistem Pendukung Keputusan Penentuan Penerimaan Raskin Menggunakan Metode Simple Additive Weighting. TEKNIKA, Volume 8, Nomor 1, Juli 2019. Pp. 75-77. 
[6] Suherdi, R.A, Taufiq. R, Yanuardi, Permana. A.A, "Penerapan Metode AHP dalam Sistem Pendukung Keputusan Kenaikan Pangkat Pegawai Di Badan Kepegawaian Dan Pengembagan Sumber Daya Manusia Kota Tangerang," in SINTAK, 2018, pp. 522-528

[7] Taufiq, R dan Sugiharto, A. 2011. The Decision Support System Design of Employee Performance Appraisal Using Analytical Hierarchi Process (AHP) Method. Proceedings of the 1st International Conference on Information Systems For Business Competitiveness (ICISBC).

[8]Bulog.2018.

http://www.bulog.co.id/sekilas raskin.php. Akses 19 Mei 2020

[9] Rastra.2020. Beras untuk keluarga sejahtera. http://raskin.bangda.kemendagri.go.id/home.h tml. Akses 19 Mei 2020 